УДК 550.42:546.49:581.1:504.7(571.14)

\title{
ГЕОХИМИЧЕСКИЕ ОСОБЕННОСТИ РАСПРЕДЕЛЕНИЯ РТУТИ В ЛИСТЬЯХ И ГОДОВЫХ КОЛЬЦАХ ТОПОЛЯ УРБАНИЗИРОВАННЫХ ТЕРРИТОРИЙ НА ПРИМЕРЕ Г. НОВОСИБИРСК
}

\author{
Турсуналиева Елена Муратовна', \\ tursunalieva.em@gmail.com
}

\section{Юсупов Дмитрий Валерьевич1,2,} yusupovd@mail.ru

\section{Рихванов Леонид Петрович ${ }^{1}$, rikhvanov@tpu.ru}

\section{Ляпина Елена Евгеньевна ${ }^{3}$, eeldv@mail.ru}

1 Национальный исследовательский Томский политехнический университет, Россия, 634050, г. Томск, пр. Ленина, 30.

2 Амурский государственный университет, Россия, 675027, Благовещенск, Игнатьевское шоссе, 21.

3 Институт мониторинга климатических и экологических систем СО РАН, Россия, 634055, г. Томск, пр. Академический, 10/3.

\begin{abstract}
Актуальность работы обусловлена необходимостью эколого-геохимической оценки техногенного воздействия на окружающую среду и здоровье населения в связи с развитием урбанизации и промышленности в городах, повлекшее за собой загрязнение поллютантами компонентов природной среды.

Цель: оценка ртутной нагрузки на природные компоненты урбанизированной территории с промышленно развитой инфрраструктурой по данным изучения листьев и керна тополя в г. Новосибирск.

Объекты: листья и годовые кольца тополя бальзамического (Populus balsamifera L.). Выбранный вид тополя широко распространен в городах умеренного пояса. Он имеет ряд особенностей, в числе которых относительно большая площадь, восковое покрытие и наличие устьии с двух сторон листовой пластины, позволяющие улавливать в значительном количестве пылевые частицы и аэрозоли, являясь индикатором состояния воздушного бассейна.

Методы: отбор проб листьев тополя во временном периоде 2014-2018 г2. по равномерной площадной сети 4×4 со сгущением 1×1 км вблизи предполагаемого источника загрязнения; отбор проб древесного керна с отдельно стоящих деревьев на расстоянии от 0,5 до 1 км от предполагаемого источника; высушивание и измельчение; атомно-абсорбционный анализ $\mathrm{Hg}$ методом пиролиза; статистическая обработка данных; построение карт и графиков.
\end{abstract}

Результаты. В ходе проведения полевых и лабораторных работ получены данные по геохимическим особенностям распределения $\mathrm{Hg}$ в листьях и годичных кольцах тополя бальзамического (P. balsamifera L.) на территории г. Новосибирск. B северо-

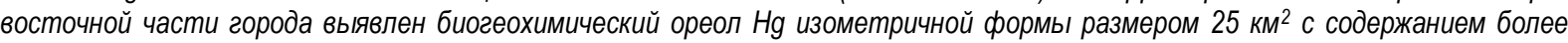
100 нг/2. Высокая концентрация $\mathrm{Hg}$ (1300 нг/2) в листьях тополя зафриксирована в 2017 г. в Калининском районе, вблизи промышленной площадки Новосибирского завода химконцентратов (НЗХК). Исследования показали четкую тенденцию увеличения накопления $\mathrm{Hg}$ в листьях тополя в течение вегетационного периода. Максимальное среднее содержание выявлено в листовом опаде - 2006 нг/2 (1153-2425 нг/2). Однако среднее содержание $\mathrm{Hg}$ в почве - 294 нг/2, что значительно ниже предельно-допустимых концентраций (2100 нг/2). Исследован характер распределения содержания $\mathrm{Hg} в$ листьях тополя по высоте кроны дерева, произрастающего в эпицентре биогеохимического ореола $\mathrm{Hg}$. С наветренной стороны от источника эмиссии концентрация $\mathrm{Hg}$ в листьях в среднем в 1,5 раза выше, чем со стороны «ветровой тени». В ходе изучения форм нахождения $\mathrm{Hg}$ в листьях тополя установлено, что $\mathrm{Hg}$ содержится преимущественно в свободной и фризически связанной формах, наиболее мобильных, склонных к повышенной миграции, трансформации и мителированию в условиях окружающей среды. По содержанию $\mathrm{Hg}$ в керне тополя установлены три периода эмиссии $\mathrm{Hg}$ вблизи источника: 1-й - с максимальной эмиссией в 1967-1985 г2., 2-ой - снижение содержания Hg в 1991-2000 г2., 3-й - сравнительно низкий уровень содержания Hg в 2000-2017 г2. В г. Новосибирске оконтурен крупный биогеохимический ореол $\mathrm{Hg}$, установлен возможньй источник её эмиссии. Методом дендробиогеохимии в эпицентре наиболее высокого содержания $\mathrm{Hg}$ установлена многолетняя динамика изменения содержания $\mathrm{Hg}$ в объектах исследования. Определен период с максимальным техногенным влиянием $\mathrm{Hg}$ на городскую среду. В селитебной и промышленной зонах на северо-востоке Новосибирска в пределах крупного биогеохимического ореола $\mathrm{Hg}$ рекомендуется постановка эколого-геохимического мониторинга со ртутнометрической съемкой атмосфрерного воздуха, исследованием почвенно-растительного покрова, контроль санитарно-гигиенических показателей состояния здоровья населения.

\section{Ключевые слова:}

Ртуть, урбанизированные территории, Новосибирск, листья тополя, годовые кольца, дендрогеохимия.

\section{Введение}

В связи с урбанизацией и быстрым развитием промышленности одной из важнейших задач эколо- гической геохимии является изучение антропогенного воздействия на объекты окружающей среды, а именно - путей поступления и поведения загрязняю- 
щих веществ, масштабов загрязнения, предотвращение или же борьба с их последствиями. С учетом самого высокого показателя токсичности $\mathrm{Hg}$ (21) среди других элементов для живых организмов и обширными вариантами ее проявлений особое значение приобретает изучение геохимии этого элемента $[1,2]$. $\mathrm{Hg}$ распространена повсеместно и негативно воздействует на окружающую среду и здоровье людей $[3,4]$. Самым распространенным соединением $\mathrm{Hg}$ в окружающей среде является сульфид ртути $\mathrm{HgS}(\mathrm{I})$ - минерал киноварь. Кроме того, встречается металлическая $\mathrm{Hg}$, ее органические производные и неорганические соединения. При вдыхании паров металлической $\mathrm{Hg}$ более 80 \% абсорбируется во внутренних органах с последующим накоплением, что приводит к отрицательному влиянию на здоровье (разрушению легких, поражению почек, печени, головного мозга, нервной системы, потеря зрения и т. д.) [5, 6]. В Российской Федерации в «Перечень загрязняющих веществ, в отношении которых применяются меры государственного регулирования в области охраны окружающей среды» входит только $\mathrm{Hg}$, как вещество первого класса гигиенической опасности в компонентах окружающей среды [6]. Но в то же время токсичный элемент и его соединения исключены из списка веществ, подверженных контролю на предприятиях [7].

На урбанизированных территориях растения играют роль естественного барьера на пути распространения загрязняющих веществ [8]. При этом значение имеет расстояние произрастания от источника, а также индивидуальные характеристики растения (высота размеры листовой пластины, наличие воскового покрытия, густота кроны и т. д.), условия окружающей среды и характер загрязнения [9-12]. Рядом исследований доказана способность отдельных видов растений избирательно накапливать загрязняющие вещества [13-15]. Объектами исследования могут служить листья, кора, древесина $[16,17]$ и корни растений. Тополь бальзамический (P. balsamifera L.) - широко используемое в качестве зеленых насаждений городов лиственное растение с высокой газопоглотительной способностью и устойчивостью к токсикантам [18]. Широкая поверхность, ворсистость и восковое покрытие листовой пластины позволяет лучше улавливать загрязняющие вещества и накапливать их ряд отличительных свойств тополя, делающих его прекрасным биоиндикатором. В ходе экспериментов, проводимых учеными разных стран, установлен основной путь поступления загрязняющих веществ в листья тополя - атмосферный воздух [19-22].

\section{Исследуемая территория}

Новосибирск - город-миллионник, расположенный на пересечении важнейших транспортных коридоров, соединяющих Европу и Азию. Третий по численности населения город РФ (1618039 чел. по данным 2019 г.), расположен в юго-восточной части Западно-Сибирской равнины. Площадь территории города - 502,7 км ${ }^{2}$ [23], располагается на обоих берегах p. Оби. Новосибирск находится в умеренно- климатическом поясе с характерным колебанием среднемесячных температур.

Новосибирск разделен на 10 административных районов, из них Первомайский и Заельцовский районы являются самыми загрязненными взвешенными веществами [24]. Максимально разовые концентрации загрязняющих веществ фиксируются и в других районах. В целом уровень загрязнения в городе оценивается как «высокий». В период с 2014 по 2018 гг. наблюдается рост уровня загрязнения атмосферного воздуха рядом веществ (взвешенные вещества, $\mathrm{C}_{20} \mathrm{H}_{12}$, $\mathrm{HCHO}, \mathrm{NO}_{2}$ ). Основной вклад в загрязнение города вносят: транспорт, теплоэнергетика, тяжелая и легкая промышленность. По данным на 2018 г., к основным загрязнителям относят: $\mathrm{NH}_{4}{ }^{+}$(ионы аммония), $\mathrm{NO}_{3}$ (нитраты), As, $\mathrm{Hg}, \mathrm{B}, \mathrm{Mn}$, фториды и фенолы [24].

Энергетический комплекс города хорошо развит и включает в себя 4 крупных тепловых электростанций (ТЭЦ) и большое количество котельных. Самой крупной теплоэлектростанцией является ТЭЦ-5.

В промышленный комплекс г. Новосибирска входят: пищевая промышленность, машиностроение, цветная металлургия, электроэнергетика, металлообработка и др. [23]. Новосибирский завод химконцентратов (НЗХК) - крупнейший завод ядернотопливного цикла в России по производству ядерного топлива, химикатов для промышленного применения и лития. На расстоянии 3 км от северо-восточной окраины города находится хвостохранилище для хранения пульпы, содержащей $\mathrm{U}, \mathrm{Hg}$, Li и твердых бытовых отходов $[25,26]$.

\section{Объекты и методы}

Для исследования ртутной нагрузки, динамики накопления Hg были отобраны пробы листьев, опада и кернов тополя бальзамического (P. balsamifera L.). Отбор проводили в 2014-2019 гг. на территории г. Новосибирск - по равномерной площадной сети $4 \times 4$ км в 2014 г., в районе биогеохимической аномалии $\mathrm{Hg}-1 \times 1$ км в 2017 г. методом средней пробы. Листья тополя отбирались в сухую погоду на высоте 1,5-2 м, согласно рекомендациям [27]. Всего было отобрано 70 биогеохимических проб.

С помощью автовышки с отдельно стоящего тополя отобраны 28 проб листьев в горизонтальном (перпендикулярном) и вертикальном направлениях относительно оси кроны через каждый метр (2-15 м) с наветренной (восточной) и подветренной (западной) сторон на расстоянии около 500 м от предполагаемого источника эмиссии $\mathrm{Hg}$. Для изучения уровня накопления металла в эпицентре аномалии в течение вегетационного периода отобрались пробы листьев тополя ежемесячно с июня по октябрь 2018 г. Всего отобрано 14 проб листьев и 10 проб листового опада.

Керн тополя отбирался в октябре 2017 г. в четырех точках с отдельно стоящих деревьев на разном удалении от источника. Пробы отбирали приростным буравом с восточной и западной стороны дерева на высоте 1,5-2 м [28] и помещали в бумажные пеналы. Отверстие в стволе дерева после извлечения керна обрабатывалось садовым варом. Количество отобран- 
ных кернов составило 10 шт. (более 200 годовых колец).

Пробы керна после сушки подвергались шлифовке, зачистке и разделению на годовые кольца с последующим измельчением при помощи скальпеля. Для точной маркировки колец использовался прибор LINTAB с программным обеспечением TSAP-Win и бинокулярный микроскоп. Измерения ширины годовых колец проводили в лаборатории динамики и устойчивости экосистем в Институте мониторинга климатических и экологических систем (ИМКЭС) СО РАН (г. Томск). После разделения каждое годовое кольцо подвергалось анализу на $\mathrm{Hg}$.

Содержание $\mathrm{Hg}$ определяли в лаборатории микроэлементного анализа в Международном инновационном научно-образовательном центре «Урановая геология» в отделении геологии Национального исследовательского Томского политехнического университета методом атомной абсорбции (метод термодеструкции) на ртутном анализаторе «РА-915М» с приставкой «ПИРО-915+» («Люмэкс»). Все отобранные пробы предварительно высушивались при комнатной температуре. Высушенные пробы листьев и листового опада тополя измельчались вручную. Нижний предел обнаружения $\mathrm{Hg}$ - 5 нг/г. Навеска пробы 20-40 мг. Погрешность анализа составила не более $12 \%$ Концентрации $\mathrm{Hg}$ приведены на 1 г сухого вещества.
Формы $\mathrm{Hg}$ определяли на том же приборе методом термодесорбции на разных температурных режимах.

Статистическая и графическая обработка данных осуществлялась посредством программ: Microsoft Exel, Statistica, CorelDraw, Surfer, Adobe Illustrator, Google Earth.

\section{Результаты и обсуждение}

В 2014-2019 гг. проведены системные исследования по оценке содержания $\mathrm{Hg}$ в листьях тополя в городах юга Сибири и Дальнего Востока [29]. В число исследуемых городов вошел г. Новосибирск, являющийся крупным промышленным центром не только Сибирского региона, но и России. В рамках исследования определено валовое содержание, формы нахождения металла, динамика его накопления в годовых кольцах тополя, изучено влияние ряда факторов - высоты кроны дерева, периода вегетации на распределение $\mathrm{Hg}$ в листьях тополя. Анализ результатов 2014 г. показал неравномерное распределение Нg с аномальными концентрациями в северо-восточной части Новосибирска, выявил площадь и условия формирования крупного биогеохимического ореола $\mathrm{Hg}$ [29].

Средняя концентрация $\mathrm{Hg}$ в листьях тополя на территории Новосибирска (таблица) 61 нг/г [28], что в 2,4 раза выше среднего регионального уровня содержания $\mathrm{Hg}$ в городах юга Сибири и Дальнего Востока [29].

Таблица. Статистические параметры концентрации $\mathrm{Hg}$ (нг/2) в сухой массе листьев тополя на территории 2. Новосибирска по данным опробования 2014 и 2017 г2.

Table. $\quad$ Statistical parameters of $\mathrm{Hg}$ concentration $(\mathrm{ng} / \mathrm{g})$ in dry poplar leaves mass within the territory of Novosibirsk from the 2014 and 2017 tests

\begin{tabular}{|c|c|c|c|c|c|}
\hline $\begin{array}{l}\text { Показатель } \\
\text { Parameter }\end{array}$ & 2014 & 2017 & $\begin{array}{l}\text { Показатель } \\
\text { Parameter }\end{array}$ & 2014 & 2017 \\
\hline \begin{tabular}{|l|} 
Среднее \\
Mean \\
\end{tabular} & $60,5 \pm 16,2$ & $198,7 \pm 29,9$ & $\begin{array}{l}\text { Стандартное отклонение } \\
\text { Standard deviation }\end{array}$ & 88,5 & 215,5 \\
\hline \begin{tabular}{|l|} 
Минимум \\
Minimum \\
\end{tabular} & 13 & 40 & \begin{tabular}{|l} 
Эксцесс \\
Excess
\end{tabular} & 10,5 & 13,4 \\
\hline $\begin{array}{l}\text { Максимум } \\
\text { Maximum } \\
\end{array}$ & 411 & 1298 & $\begin{array}{l}\text { Коэффициент вариации, \% } \\
\text { Variation coefficient }\end{array}$ & 146 & 721 \\
\hline \begin{tabular}{|l|} 
Медиана \\
Median \\
\end{tabular} & 30,2 & 139,6 & \begin{tabular}{|l|} 
Региональный фон [Юсупов, 2018] \\
Regional background [Yusupov, 2018]
\end{tabular} & & \\
\hline \begin{tabular}{|l} 
Кларк Нg в наземных растениях \\
[Добровольский, 2003] \\
Clark Hg in land plant \\
[Dobrovolskiy, 2003] \\
\end{tabular} & \multicolumn{2}{|c|}{12,0} & $\begin{array}{l}\text { Фоновое содержание в листьях дере- } \\
\text { вьев [Иванов, 1997] } \\
\text { Background concentration in the leaves } \\
\text { of the trees [Ivanov, 1997] }\end{array}$ & \multicolumn{2}{|c|}{17,0} \\
\hline
\end{tabular}

Такие высокие концентрации объясняются высокой транспортной нагрузкой, развитой промышленностью, электроэнергетикой, отдельными крупными предприятиями (в технологическом процессе которых используется $\mathrm{Hg}$ ), организованными и несанкционированными свалками. Кроме того, в годы проведения экспериментальных исследований летние периоды характеризовались повышенными средними температурами воздуха, что способствовало испарению паров накопленной сферами экосистемы города $\mathrm{Hg}$. Самым незагрязненным $\mathrm{Hg}$ районом оказался Первомайский, расположенный в южной части левобережья города. На втором месте Ленинский и Октябрьский районы со средним значениме $\mathrm{Hg}$ (30 нг/г) [28], ненамного превышающим региональный фон [29]. Не смотря на расположение в данных районах большей части промышленных предприятий, можно считать их относительно чистыми по данным ртутного анализа 2014 г.

Максимальное значение (411 и 323 нг/г) приходится на точки, расположенные на территории Калининской промышленной зоны в северо-восточной части города, в непосредственной близости от санитарно-защитной зоны промышленной площадки ПАО «НЗХК» и ТЭЦ-4 [29].

На рис. 1, а показаны биохимические ореолы $\mathrm{Hg}$ в г. Новосибирск. Концентрации $\mathrm{Hg}$ на территории левого берега и юго-востоке правого берега р. Объ не превышают $40 \mathrm{Hг} / \Gamma$, тогда как в северной части правобережья можно выделить очаг с высоким содержанием $\mathrm{Hg}$ (более 100 нг/г) [29]. 


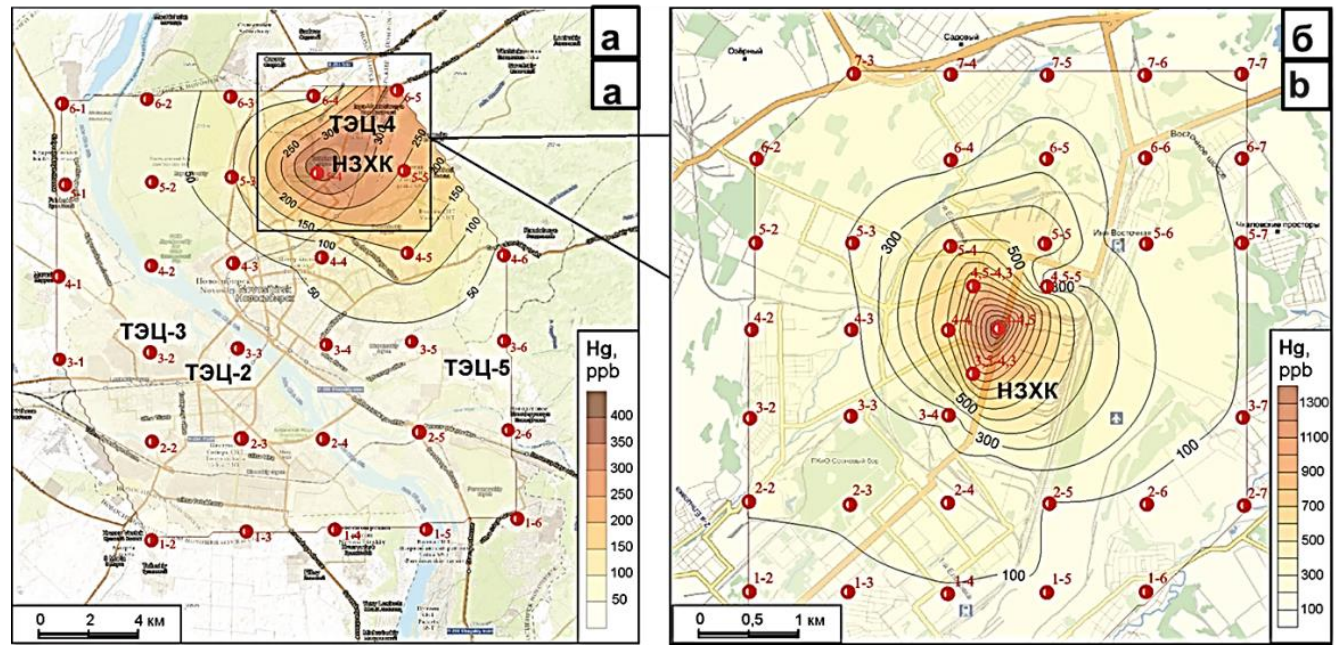

Pис. 1. Ореоль Hg в г. Новосибирск в сухой массе листьев тополя по даннымм 2014 (а) и 2017 (б) г2. [29]

Fig. 1. Hg halos in the city of Novosibirsk as established from dry poplar leaves mass, data for 2014 (a) and 2017 (b) [29]

В 2017 г. на для проверки содержаний $\mathrm{Hg}$ на территории обнаруженной в 2014 г. аномалии были дополнительно отобраны пробы листьев тополя. Сеть охватила часть Калининского и Дзержинского районов. Результаты показали максимально высокую концентрацию Нg вблизи северо-западной границы промышленной площадки ПАО «НЗХК» (рис. 1, б). Максимальное значение (1298 нг/г) (таблица) превышает региональный фон $(25$ нг/г) в 52 раза, и среднее значение по всей территории г. Новосибирск $(60$ нг/г) - В 26 раз [29].

Расчёты геоэкологических показателей концентраций $\mathrm{Hg}$ в листьях тополя на исследуемой территории показали значительное превышение относительно регионального фона (Фр.) [29], кларка $\mathrm{Hg}$ в наземных растениях (Кн.р.) [30] и фоновых содержаний в листьях деревьев (Фл.д.) [31]. Так, результаты исследования 2014 г. выявили превышения относительно Фр. в 5,1; Кн.р. - в 2,4; Фл.д. - 3,6 раза. Данные ис- следований в выделенной аномалии 2017 г. характеризуются более высокими цифрами кратности превышения: 16,6; 8 и 11,7 соответственно. Полученные цифры свидетельствуют о значительном биологическом накоплении $\mathrm{Hg}$ листьями тополя на территории г. Новосибирск.

Осенью 2017 г. для оценки вклада антропогенного фактора, влияющего на состояние окружающей среды и динамики загрязнения $\mathrm{Hg}$, были отобраны пробы древесного керна в непосредственной близости от предполагаемого источника загрязнения. Годовые кольца позволяют улавливать концентрацию $\mathrm{Hg}$ в течение всего года, в отличие от листьев, являющихся сезонным биоиндикатором [28]. Однако источник поступления $\mathrm{Hg}$ в листья и древесину тополя разный.

В исследованных годовых кольцах временной период накопления $\mathrm{Hg}$ составляет 50 лет. При этом выделяется три интервала, среднее содержания $\mathrm{Hg}$ в которых значимо отличается друг от друга (рис. 2).

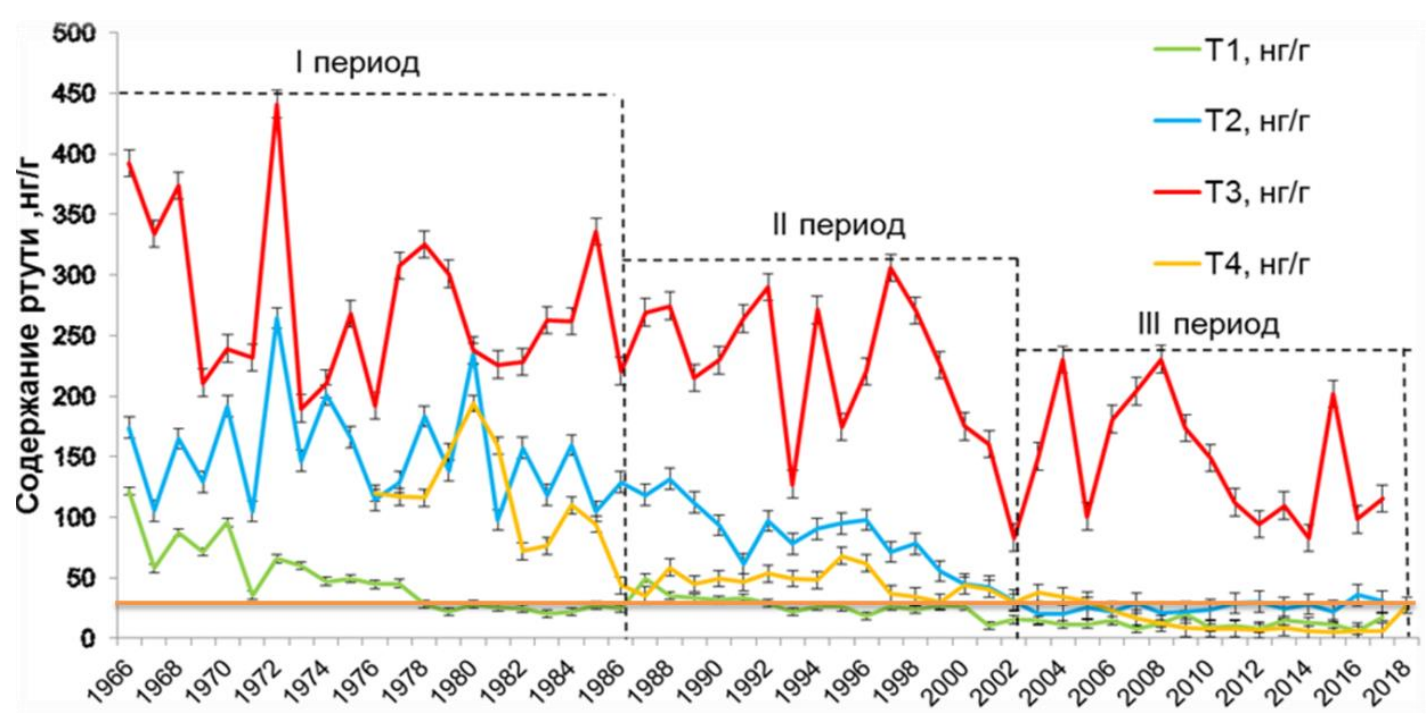

Pис. 2. Динамика поступления Hg в годовых кольцах тополя. Оранжевая линия - региональный фон (25 нг/2) [29]. Расстояние от источника загрязнения: $T 1-700$ м, T2 -600 м. T3 - 480м, T4 - 900 м

Fig. 2. Dynamics of $\mathrm{Hg}$ uptake as determined from poplar annual rings. The orange line represents a regional background value $(25 \mathrm{ng} / \mathrm{g})$ [29]. Distance from pollution source: $\mathrm{T1}-700 \mathrm{~m}, \mathrm{T2}-600 \mathrm{~m}, \mathrm{T3}-480 \mathrm{~m}, \mathrm{T4}-900 \mathrm{~m}$ 
Период с самым низким содержанием $\mathrm{Hg}$ (6 нг/г) с 2018 по 2002 гг. Временной интервал с самыми высокими значениями содержания $\mathrm{Hg}$ (441 нг/г) приходится на 1966-1986 гг. С 1987 по 2001 гг. происходит постепенное снижение средних концентраций $\mathrm{Hg}$ в интервале 152-98 нг/г. Похожий характер накопления $\mathrm{Hg}$ деревьями отражает динамику ртутной нагрузки на окружающую среду города.

Минимальные средние значения концентрации $\mathrm{Hg}$ в кернах тополя в зоне воздействия промышленного объекта выпадают на точку 1 (32 нг/г) и точку 4 (52 нг/г), расположенные на самом дальнем расстоянии от предполагаемого источника. Минимальные концентрации $\mathrm{Hg}$ в вышеуказанных точках относятся к 2016-2017 гг. Относительно других первая точка характерна низкими концентрациями (6 нг/г) в течение всего анализируемого периода. Максимальные концентрации $\mathrm{Hg}$ выявлены в точке 3, которая находится в 480 м от предполагаемого источника.

Такой скачок концентраций $\mathrm{Hg}$ можно объяснить близким расположением ПАО «НЗХК», который в 60-х гг. XX в. запустил процесс литиевого производства [32]. Также возможно влияние золоотвала и ТЭЦ-4 за счет введения в строй новых агрегатов. В период с середины 50-х по начало 70-х, отмечается рост генерирующих мощностей электростанции [23]. Следует отметить, что ореол загрязнения $\mathrm{Hg}$ совпадает с таковым для U, природа которого техногенная, что подтверждает протяженный на 70 км в северовосточном направлении (по розе ветров) ореол с пониженным отношением $238 \mathrm{U} / 235 \mathrm{U}$ по результатам снеговых съемок С.А. Артамоновой [33]. Поэтому рядом расположенная ТЭЦ не может быть поставщиком U в компоненты природной среды. Доказано, что выбросы НЗХК поставляют в окружающую среду U как в рассеянном виде, так и в виде микрочастиц оксидов U размером до 10 мкм [34].

Исследование особенностей накопления $\mathrm{Hg}$ кроной тополя в зависимости от высоты отбора проб и ориентации дерева относительно источника показали «полосатый» характер распределения концентраций Hg (рис. 3).

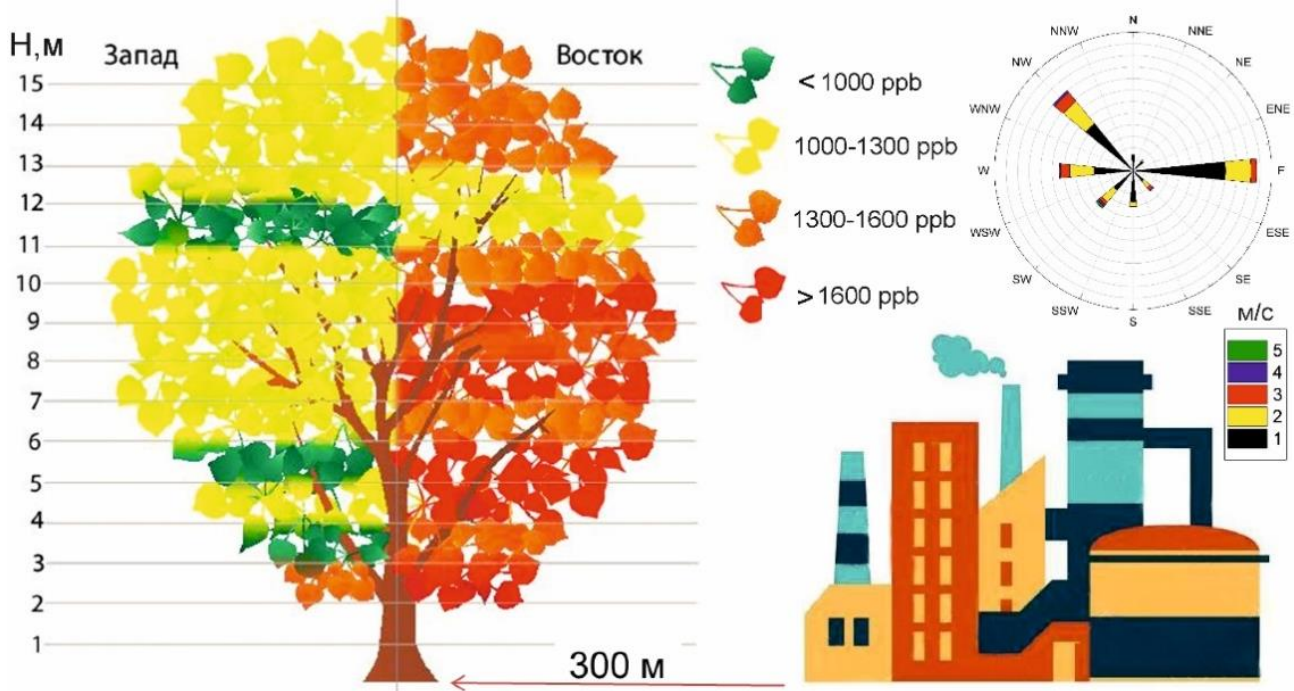

Рис. 3. Выявление характера распределения Hg по высоте кроны дерева ( $p p b=н г / 2)$

Fig. 3. Determining the nature of $\mathrm{Hg}$ distribution through the tree crown height ( $p p b=n g / g$ )

В ходе эксперимента обнаружено превышение концентрации $\mathrm{Hg}$ в пробах листьев тополя в среднем в 1,5 раза с наветренной стороны кроны над подветренной, что объясняется расположением источника загрязнения $\mathrm{Hg}$ к востоку от опробованного дерева. Однако на высоте 2-3 м (рекомендованная высота отбора проб) концентрация с двух сторон отличается от 1,3 до 1,6 раза. При этом следует отметить, что на высотах 3-4, 5-7 и 11-13 м крону исследуемого тополя опоясывают «ленты» шириной 1-2 м, где концентрации $\mathrm{Hg}$ в 1,3 раза ниже по сравнению с остальной кроной, как с восточной, так и западной стороны (рис. 3). По результатам исследования выявили уменьшение накопления $\mathrm{Hg}$ кроной тополя с высотой, что подтверждает роль подстилающей поверхности в качестве вторичного источника поллютанта в листве.

Вегетационный период у большинства деревьев начинается при наступлении положительных темпе- ратур весной в дневное время. В переходный весенний период корни деревьев только начинают заново расти, однако наземная часть уже активна. В крону начинают поступать тепло и влага, что положительно влияет на развитие дерева в период вегетации и созревание плодов.

Собственно, сам вегетационный период, который на большей территории России длиться с мая по сентябрь включительно, является самым длительным периодом. У деревьев вегетация - время активной жизнедеятельности, которое характеризуется началом движения соков, распусканием почек, образованием небольших побегов, появлением бутонов, цветением, плодоношением, образованием семян, вплоть до сбрасывания листьев. В середине вегетационного периода рост дерева уже не такой активный. Однако листья продолжают функционировать, поэтому в растении и плодах накапливается крахмал, побеги дерева 
покрываются древесиной, корневая система становится менее активна.

В переходный осенний период завершается покрытие древесиной побегов дерева. Крахмал, накопленный во всех частях растения, превращается в сахар, обеспечивая устойчивость растения во время зимы. В течение всего периода идет активный рост мелких всасывающих корней, продолжающийся до самых морозов [35].

В меняющихся условиях городской среды и в связи с высокими концентрациями $\mathrm{Hg}$ и их варьированием вблизи источника загрязнения был проведен ряд исследований для выявления особенностей накопления $\mathrm{Hg}$ листьями в течение вегетационного периода. Результаты эксперимента по изучению динамики содержания Hg в течение летне-осеннего периода 2017 г. показали четкую тенденцию по увеличению концентрации элемента. Самое низкое содержание $\mathrm{Hg}$ выявили в пробах, отобранных в конце июня (601 нг/г). К концу вегетационного периода (сентябрь) $\mathrm{CHg}$ увеличилась в 3,2 раза и составила 1938 нг/г в пожелтевших листьях, максимальное значение обнаружилось в листовом опаде - 2425 нг/г, собранном в октябре. Увеличение содержания Нg в пробах листьев к концу вегетации объясняется физиологическими особенностями дерева и накопительным эффектом. Максимальные содержания в опаде характеризуются потерей влаги листьями и, как следствие, концентрированием Нg.

Валовое содержание $\mathrm{Hg}$ отражает общее поступление и накопление $\mathrm{Hg}$ листьями и древесиной тополя. Однако наибольший интерес и опасность представляют формы нахождения $\mathrm{Hg}$ в компонентах окружающей среды. Поскольку именно формы нахождения $\mathrm{Hg}$ определяют степень ее токсичности и негативного воздействия на атмосферный воздух, почву, поверхностные и подземные воды, биоту и человека. В исследованных пробах листьев, опада и почв в точках опробования преобладающей $\mathrm{Hg}$ присутствует в основном в свободной форме $\left(\mathrm{Hg}^{0}\right)$, а также физически и химически связанная.

Было выявлено, что свободная форма $\mathrm{Hg}\left(\mathrm{Hg}^{0}\right)$ является преобладающей в зоне выявленной ртутной аномалии и составляет от 4 до 100 \% в исследованных пробах листьев, листового опада и почвы. При этом следует отметить, что Нg в газообразной форме обнаружена в 83 \% проб листьев в результате площадной оценки ртутной нагрузки на территории повышенного содержания. При оценке поступления разных соединений $\mathrm{Hg}$ в листовую пластину в зависимости от расположения дерева относительно источника свободная форма $\mathrm{Hg}$ также отмечается в 83 \% случаев, особенно с той стороны дерева, которая развернута от источника. В листьях тополя с той стороны кроны дерева, которая развернута к источнику, $\mathrm{Hg}$ присутствует как в атомарном состоянии, так и физически связана с пылеаэрозольными частицами (рис. 4). В листовом опаде и пробах почв в зоне высоких содержаний $\mathrm{Hg}$ элемент также в основном присутствует в виде $\mathrm{Hg}^{0}(83-100 \%)$.
Физически связанная форма в качестве преобладающей во всех изученных пробах встречается реже $\left(\mathrm{HgCl}_{2}\right)$. Кроме того, большинство исследованных проб листьев, опада, почв характеризуются присутствием в основном двух форм $\mathrm{Hg}$ - свободной и физически связанной. Данные соединения $\mathrm{Hg}$ являются наиболее способными к миграции и трансформации, а, следовательно, наиболее опасными с точки зрения геоэкологии. Стоит отметить также присутствие сульфидной (12\%) и изоморфной (7-9 \%) форм Нg в листьях тополя. Данные соединения относятся к наиболее устойчивым в природной среде, но источник их поступления антропогенный.

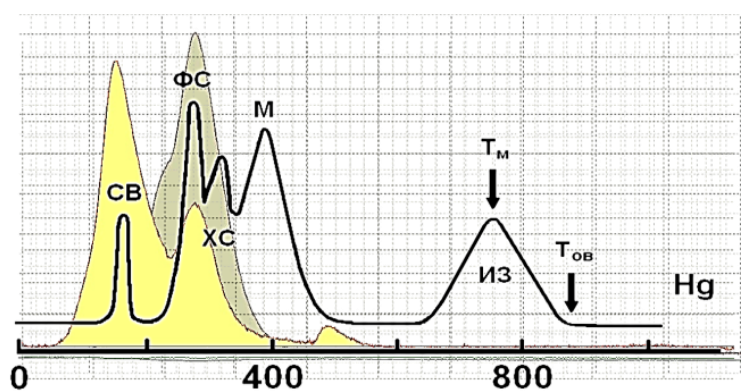

Puc. 4. Схема распределения форм $\mathrm{Hg}$ в пробах листьев тополя. Условные обозначения форм $\mathrm{Hg}$ : $\mathrm{CB}-$

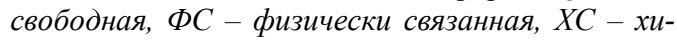
мически связанная, $М$ - сульфидная, ИЗ - изоморфная

Fig. 4. Scheme of distribution of $\mathrm{Hg}$ forms in poplar leaves samples. Symbols of forms of $\mathrm{Hg}$ : $C B-$ free, $\Phi C-$ physically bonded, XC - chemically bonded, $M-$ sulfide, ИЗ - isomorphic

Лишь некоторые точки отличаются присутствием всех форм Нg в исследованных пробах. В пространстве данные точки расположены в центральной части выявленного очага $\mathrm{Hg}$, а также в северо-восточной и северо-западной частях.

Поступление разных форм $\mathrm{Hg}$ в листовую пластину с высотой характеризуется общим соотношением максимум свободной $\mathrm{Hg}$, затем физически и химически связанная $\mathrm{Hg}$. Однако с наветренной стороны кроны на высотах 5 и 15 м поллютант присутствует в основном в физически связанных формах.

Кроме того, формы $\mathrm{Hg}$ в листовой пластине тополя в течение всего вегетационного периода подвергаются изменению. В пробах, отобранных в июне, преобладает физически связанной форма $\mathrm{Hg}$ (до $67 \%$ ), присутствует свободная форма (до $32 \%$ ) и менее $1 \%$ химически связанная и сульфидная формы $\mathrm{Hg}$. В конце вегетационного периода первые две формы меняются местами.

В почвах в центре очага валовые содержания $\mathrm{Hg}$ составляют 295 нг/г. Что касается соединений $\mathrm{Hg}$, то почвы характеризуются присутствием четырех форм: свободная, физически и химически связанная, а также изоморфная. Преобладающей является свободная $\mathrm{Hg}$. Это значит, что почвы в очаге повышенного содержания могут выступать в качестве вторичного источника поступления $\mathrm{Hg}$ в растения и атмосферный воздух. 


\section{Заключение}

В г. Новосибирске оконтурен крупный биогеохимический ореол $\mathrm{Hg}$, установлен возможный источник её эмиссии. Методом дендрогеохимии в эпицентре наиболее высокого содержания $\mathrm{Hg}$ установлена многолетняя динамика изменения содержания $\mathrm{Hg}$ в объектах исследования. Определен период с максимальным техногенным влиянием $\mathrm{Hg}$ на городскую среду. В селитебной и промышленной зонах на северовостоке Новосибирска в пределах крупного биогеохимического ореола $\mathrm{Hg}$ рекомендуется организация эколого-геохимического мониторинга с ртутнометрической съемкой атмосферного воздуха, исследованием почвенно-растительного покрова, контролем санитарно-гигиенических показателей состояния здоровья

\section{СПИСОК ЛИТЕРАТУРЫ}

1. Янин Е.П. Ртуть в окружающей среде промышленного города. - М.: ИМГРЭ, 1992. - 169 с.

2. Аношин Г.А., Маликова И.Н., Ковалев С.И. Ртуть в окружающей среде юга Западной Сибири // Химия в интересах устойчивого развития. -1995 . - Т. 3. - № 1-2. - С. 69-111.

3. Global anthropogenic mercury emission inventory for 2000 E.G. Pacyna, J.M. Pacyna, F. Steenhuisen, S. Wilson // Atmospheric Environment. - 2006. - V. 40 (20). - P. 4048-4063.

4. Scenarios of global mercury emissions from anthropogenic sources / P. Rafaj, I. Bertok, J. Cofata, W. Schopp // Atmospheric Environment. - 2013. - V. 79. - P. 472-479.

5. Петросян В.С. Глобальное загрязнение окружающей среды ртутью и ее соединениями // Россия в окружающем мире: 2006 (аналитический ежегодник) / отв. ред. Н.Н. Марфенин / под общ. ред. Н.Н. Марфенина, С.А. Степанова. - М.: МНЭПУ, 2007. - С.149-163.

6. Перечень загрязняющих веществ, в отношении которых применяются меры государственного регулирования в области охраны окружающей среды. Распоряжение Правительства Российской Федерации от 8 июля 2015 г. № 1316-p. URL: http://government.ru/media/files/NQsLnpwkA9vtceGoj46TRcTS m6yxJXmH.pdf (дата обращения 11.01.2020).

7. Пилотный проект по формированию кадастра ртутных загрязнений в РФ. URL: https://docplayer.ru/56639052-Rezultatyvypolneniya-pilotnogo-proekta-po-sozdaniyu-kadastra-rtutnyhzagryazneniy-okruzhayushchey-sredy-v-rossiyskoy-federacii.html (дата обращения 20.12.2019).

8. Air pollution abatement performances of green infrastructure in open road and built-up street canyon environments / K.V. Abhijith, K. Prashant, J. Gallagher, A. McNabola // Atmospheric Environment. - 2017. - V. 162. - P. 71-86.

9. Mercury dynamics of a northern hardwood canopy / J. Bushey, A. Nallana, M. Montesdeoca, C. Driscoll // Atmospheric Environment. - 2008. - V. 42. - P. 6905-6914.

10. Процесс загрязнения ртутью кроны деревьев и оценка её сезонного накопления на условно чистой и урбанизированной территориях / В.П. Зволинский, В.А. Андрианов, Л.И. Ермакова, Е.Г. Булаткина // Известия Нижневолжского агроуниверситетского комплекса: наука и высшее профессиональное образование. - 2015. - № 3 (39). - С. 26-29.

11. Air/surface exchange of mercury vapor over forests - the need for a reassessment of continental biogenic emissions / S. Lindberg, P. Hanson, T. Meyers, K. Kim // Atmospheric Environment. 1998. - V. 32 (5). - P. 895-908.

12. Foliar exchange of mercury-vapor - evidence for a compensation point / P. Hanson, S. Lindberg, T. Tabberer, J. Owens, K. Kim // Water, Air, and Soil Pollution. - 1995. - V. 80 (1-4) - P. 373-382.

13. Fine-scale mercury trends in temperate deciduous tree leaves from Ontario, Canada / E. Siwik, L. M. Campbell , G. Mierle // Science of the Total Environment. - 2009. - V. 407 - P. 6275-6279.

14. Особенности накопления тяжелых металлов в листьях древесных растений на урбанизированных территориях в условиях севера / Л.В. Ветчинникова, Т.Ю. Кузнецова, А.Ф. Титов // Тр. Карел. науч. центра РАН. - 2013. - № 3. - С. 68-73. населения. Результаты исследования подтверждают индикаторные свойства листьев тополя, возможность использования этого объекта в биогеохимическом мониторинге для оценки загрязнения окружающей среды (приземного воздуха) Hg, говорят о необходимости разработки ориентировочно допустимых концентраций (ОДК) Hg и других химических элементов-поллютантов в растительных объектах мониторинга.

Научные исследования выполнены в рамках программы повышения конкурентоспособности ТПУ среди ведущих мировых исследовательских иентров. Определение форм нахождения ртути в образцах листьев тополя, листового опада и почв выполнено в рамках проекта № AAAA-A17117013050031-8.

15. Пац А.Ч., Сосновская Н.Е. Особенности аккумуляции пыли и тяжелых металлов древесными растениями в техногенных условиях (на примере г. Гродно) // Природопользование: состояние и перспективы развития: материалы конф. молод. ученых. - Минск, 2014. - С. 71-75.

16. Evaluation of historical atmospheric pollution in an industrial area by dendrochemical approaches / A. L. Austruya, L. Yungc, J.P. Ambrosib, O. Girardclosc, C. Kellerb, B. Angelettib, J. Dron, P. Chamareta, M. Chalotc // Chemosphere. - 2019. - V. 220. P. 116-126.

17. The history of mercury pollution near the Spolana chlor-alkali plant (Neratovice, Czech Republic) as recorded by Scots pine tree rings and other bioindicators / N. Tomas, S. Martin, B.S. James, R. Jan, H. Maria, H. Jakub // Science of The Total Environment. 2017. - V. 586. - P. 1182-1192.

18. Гетко Н.В., Шобанова И.А., Жданец С.Ф. Устойчивость интродуцированных растений к газообразным соединениям серы // Оптимизация окружающей среды средствами озеленения. (Промышленные центры Белоруссии). - Минск: Наука и техника, 1985. - С. 60-68.

19. Mercury uptake into poplar leaves / M. Assad, J. Parelle, D. Cazaux, F. Gimbert, M. Chalot, F. Tatin-Froux // Chemosphere. - 2016. - № 146. - P. 1-7.

20. Laacour A., Nater E.A., Kolka R.K. Distribution and uptake dynamics of mercury in leaves of common deciduous tree species in Minnesota, U.S.A. // Environmental Science \& Technology. 2013. - V. 47. - P. 10462-10470.

21. Accumulation of atmospheric mercury in forest foliage / J.A. Ericksen, M.S. Gustin, D.E. Schorran, D.W. Johnson, S.E. Lindberg, J.S. Coleman // Atmospheric Environment. 2003. - V. 37. - P. 1613-1622.

22. Foliar heavy metal uptake, toxicity and detoxification in plants: A comparison of foliar and root metal uptake / S. Muhammad, D. Camille, K. Sana, S. Eva, X. Tiantian, K.N. Nabeel // Journal of Hazardous Materials. - 2017. - V. 325. - P. 36-58.

23. Официальный сайт города Новосибирск. URL: http://novosibirsk.ru (дата обращения 10.01.2020).

24. О состоянии и об охране окружающей среды Новосибирской области в 2018 году URL: https://www.nso.ru/page/2624 (дата обращения 11.01.2020).

25. Девятова А.Ю. Тяжелые металлы в депонирующих средах и прогнозная модель переноса примесей от стационарных техногенных источников: на примере г. Новосибирска: автореферат дис. ... канд. геол.-минерал. наук. - Новосибирск, 2006. $22 \mathrm{c}$.

26. Состояние окружающей природной среды в Новосибирской области в 2000 году: доклад департамента природных ресурсов по Сибирскому региону / под ред. Г.В. Селиверстова, В.Ю. Александрова. - Новосибирск, 2001. - 144 с.

27. Зырин Н.Г., Малахов С.Г. Методические рекомендации по проведению полевых и лабораторных исследований почв и растений при контроле загрязнения окружающей среды металлами / под ред. д-ра биол. наук Н.Г. Зырина. - М.: Гидрометеоиздат: Моск. отд-ние, 1981 - 110 с. 
28. Методы дендрохронологии / С.Г. Шиятов, Е.А. Ваганов, А.В. Кирдянов, В.Б. Круглов, В.С. Мазепа, М.М. Наурзбаев, Р.М. Хантемиров. - Красноярск: КрасГУ, 2000. - 80 с.

29. Ртуть в листьях тополя на урбанизированных территориях Юга Сибири и Дальнего Востока / Д.В. Юсупов, Л.П. Рихванов, Ю.В. Робертус, Е.Е. Ляпина, Е.М. Турсуналиева, Н.В. Барановская, Н.А. Осипова // Экология и промышленность России. - 2018. - Т. 22. - № 12. - С. 56-62

30. Добровольский В.В. Основы биогеохимии. - М.: ИЦ «Академия», 2003. $-400 \mathrm{c}$.

31. Иванов В.В. Экологическая геохимия элементов. Справочник. - М.: Экология, 1997. - $576 \mathrm{c}$.

32. Официальный сайт HЗXК. URL: http://www.nccp.ru (дата обращения 11.01.2020).
33. Артамонова С.Ю. Уран и торий в аэрозольных выпадениях г. Новосибирска и его окрестностей (Западная Сибирь) // Известия Томского политехнического университета. Инжиниринг георесурсов. - 2020. - Т. 331. - № 7. - С. 212-223.

34. Радиоактивные элементы (торий, уран) в листьях тополя на урбанизированных территориях и их индикаторная роль / Д.В. Юсупов, Л.П. Рихванов, А.Ф. Судыко, Н.В. Барановская, Л.А. Дорохова // Разведка и охрана недр. - 2019. - № 2. C. 61-68.

35. Все о вегетационном периоде растений: сроки, методы воздействия URL: https: //ferma.expert/rasteniya/vegetacionnyjperiod-rastenij/ (дата обращения 24.02.2020).

Потупила 23.03.2020 2.

\section{Информация об авторах}

Tyрсуналиева E.M., аспирант отделения геологии Инженерной школы природных ресурсов Национального исследовательского Томского политехнического университета.

Юсупов Д.В., кандидат геолого-минералогических наук, доцент кафедры геологии и природопользования, Амурский государственный университет.

Рихванов Л.П. , доктор геолого-минералогических наук, профессор отделения геологии Инженерной школы природных ресурсов Национального исследовательского Томского политехнического университета.

Ляпина E.E., кандидат геолого-минералогических наук, старший научный сотрудник лаборатории физики климатических систем, Институт мониторинга климатических и экологических систем СО РАН. 
UDC 550.42:546.49:581.1:504.7(571.14)

\title{
GEOCHEMICAL CHARACTERISTICS OF MERCURY DISTRIBUTION IN POPLAR LEAVES AND ANNUAL RINGS OF URBANIZED TERRITORIES ON THE EXAMPLE OF NOVOSIBIRSK
}

\author{
Elena M. Tursunalieva 1 , \\ tursunalieva.em@gmail.com \\ Dmitry V. Yusupov1,2, \\ yusupovd@mail.ru \\ Leonid P. Rikhvanov ${ }^{4}$, \\ rikhvanov@tpu.ru
}

Elena E. Lyapina ${ }^{3}$,

eeldv@mail.ru

${ }^{1}$ National Research Tomsk Polytechnic University,

30, Lenin avenue, Tomsk, 634050, Russia.

2 Amur State University,

21, Ignatievskoe highway, Blagoveshchensk, 675027, Russia.

3 Institute of Monitoring of Climatic and Ecological Systems of the Siberian Branch of the Russian Academy of Sciences, 10/3, Academichesky avenue, Tomsk, 634055, Russia.

Relevance of the study is determined by the necessity to provide ecological and geochemical assessment of technogenic impact on environment and population health related to urbanization and industrial development resulting in contamination of natural assets with various pollutants.

The aim of the study is to assess mercury loads onto the natural components of an urbanized territory with a well-developed industrial infrastructure by studying leaves and cores of balsam poplar (P. balsamifera L.).

Subjects of research are poplar leaves and annual rings. This species of poplar is very common in urban localities of temperate zone. It has a number of features allowing it to capture significant amounts of dust particles and aerosols, namely, relatively large area, wax covering and presence of both abaxial and adaxial stomata; the tree serves as an indicator of community air.

Research methods were sampling of poplar leaves through the period of 2014-2018 and following a $4 \times 4$ uniform area grid with a further concentration of $1 \times 1 \mathrm{~km}$ near assumed pollution sources; sampling of wood from separate trees at a distance of 0,5 to $1 \mathrm{~km}$ from the assumed pollution source; atomic absorption spectrometry of $\mathrm{Hg}$ by pyrolysis; statistical processing of data; plotting maps and graphs.

Results. During the field and laboratory works, the authors have obtained the data on geochemical features of $\mathrm{Hg}$ distribution through the leaves and annual rings of balsam poplar (P. balsamifera L.) in the territory of the city of Novosibirsk. In the northwestern part of the city, a biogeochemical halo of $\mathrm{Hg}$ concentrations was identified; it is isometric in form, has an area of approximately $25 \mathrm{~km}^{2}$ and is characterized by $\mathrm{Hg}$ content of over $100 \mathrm{ng} / \mathrm{g}$. In 2017, a high Hg concentration (1300 ng/g) in poplar leaves was recorded in Kalininsky district, near the industrial site of the Novosibirsk Chemical Concentrates Plant. The studies have shown a clear trend for $\mathrm{Hg}$ accumulation in poplar leaves throughout the vegetation period. Maximum average content was found in leaf litter at $2006 \mathrm{ng} / \mathrm{g}$ (the range is 1153-2425 $\mathrm{ng} / \mathrm{g}$ ). However, the average $\mathrm{Hg}$ content in soil is $294 \mathrm{ng} / \mathrm{g}$, which is significantly lower than the maximum allowable concentration of $2100 \mathrm{ng} / \mathrm{g}$. Distribution of $\mathrm{Hg}$ content in poplar leaves depending on leaf position in the tree crown was studies for a tree in the epicenter of biogeochemical halo of $\mathrm{Hg}$ concentrations. Upwind the emission source, $\mathrm{Hg}$ concentration in the leaves is on average 1,5 times higher than in the wind shadow. During the studies of $\mathrm{Hg}$ forms in poplar leaves it was established that $\mathrm{Hg}$ is primarily found in free and physically-bound forms, which are the most mobile, prone to increased migration, transformation and methylation under the environmental conditions. Studies of wood cores in the vicinity of the pollution source allowed establishing three periods of $\mathrm{Hg}$ emission: the first period, with the maximum emission covers 1967-1985, the second period of 1991-2000 shows a decrease in Hg content; the third period of 2000-2007 is characterized with a relatively low level of $\mathrm{Hg}$ concentration.

A large biogeocheimcal halo of $\mathrm{Hg}$ concentrations was mapped in the city of Novosibirsk, a possible emission source was found. Dendrobiogeochemical methods applied in the epicenter of the area with the highest mercury content allowed establishing long-term dynamics in $\mathrm{Hg}$ content in the subjects of the study. A period with the highest technogenic impact on the urban environment was established. In residential and industrial zones in the northeast of Novosibirsk, in the territory of a large biogeochemical Hg-related halo, the authors recommend to establish environmental and geochemical monitoring with mercury metering of air samples, studies of soil and plant cover, monitoring of sanitary and hygienic indicators of population's health.

\section{Key words:}

$\mathrm{Hg}$, urban territories, Novosibirsk, poplar leaves, annual rings, dendrobiogeochemistry.

The research was carried out within the Program of enhancement of TPU competitiveness among the leading world's research centers. $\mathrm{Hg}$ occurrence forms in poplar leaves samples, leaf litter and soil were determined within the project no. AAAA-A17117013050031-8. 


\section{REFERENCES}

1. Yanin E.P. Rtut v okruzhayushchey srede promyshlennogo goroda [Mercury in the environment of an industrial city]. Moscow, IMGRE Publ., 1992. 167 p.

2. Anoshin G.A., Malikova I.N., Kovalev S.I. Rtut v okruzhayushchey srede yuga Zapadnoy Sibiri [Mercury in the environment of southern Western Siberia]. Khimiya $v$ interesakh ustoychivogo razvitiya, 1995, vol. 3, no. 1-2, pp. 69-111.

3. Pacyna E.G., Pacyna J.M., Steenhuisen F., Wilson S. Global anthropogenic mercury emission inventory for 2000. Atmospheric Environment, 2006, vol. 40 (22), pp. 4048-4063.

4. Rafaj P., Bertok I., Cofata J., Schopp W. Scenarios of global mercury emissions from anthropogenic sources. Atmospheric Environment, 2013, vol. 79, pp. 472-479.

5. Petrosyan V.S. Globalnoe zagryaznenie okruzhayushchey sredy rtutyu i ee soedineniyami [Global pollution of the environment with mercury and its compounds]. Rossiya $v$ okruzhayushchem mire: 2006 [Russia in the environment]. Moscow, MNEPU Publ., 2007. pp. 149-163.

6. Perechen zagryaznyayushchikh veshchestv, $v$ otnoshenii kotorykh primenyayutsya mery gosudarstvennogo regulirovaniya $v$ oblasti okhrany okruzhayushchey sredy [The list of pollutants in relation to which the measures of state regulation in the field of environmental protection are applied]. Order of the Government of the Russian Federation dated July 8, 2015 No. 1316-r]. Available at: http:/government.ru/media/files/NQsLnpwkA9vtceGoj46TRcTS m6yxJXmH.pdf. (accessed 11 January 2020).

7. Pilotny proekt po formirovaniyu kadastra rtutnykh zagryazneniy $v$ $R F$ [A pilot project for the formation of an inventory of mercury pollution in the Russian Federation]. Available at: https:// docplayer.ru/56639052-Rezultaty-vypolneniya-pilotnogo-proektapo-sozdaniyu-kadastra-rtutnyh-zagryazneniy-okruzhayushcheysredy-v-rossiyskoy-federacii.html (accessed 20 December 2019).

8. Abhijith K.V., Prashant K., Gallagher J., McNabola A. Air pollution abatement performances of green infrastructure in open road and built-up street canyon environments. Atmospheric Environment, 2017, vol. 162, pp. 71-86.

9. Bushey J., Nallana A., Montesdeoca M., Driscoll C. Mercury dynamics of a northern hardwood canopy. Atmospheric Environment, 2008, vol. 42, pp. 6905-6914.

10. Zvolinskiy V.P., Andrianov V.A., Ermakova L.I., Bulatkina E.G. The process of mercury contamination of tree crowns and assessment of its seasonal accumulation in relatively clean and urban areas. Izvestiya Nizhnevolzhskogo agrouniversitetskogo kompleksa: nauka $i$ vysshee professionalnoe obrazovanie, 2015, no. 3 (39), pp. 26-29. In Rus.

11. Lindberg S., Hanson P., Meyers T., Kim K. Air surface exchange of mercury vapor over forests - the need for a reassessment of continental biogenic emissions. Atmospheric Environment, 1998, vol. 32 (5), pp. 895-908

12. Hanson P., Lindberg S., Tabberer T., Owens J., Kim K. Foliar exchange of mercury-vapor - evidence for a compensation point. Water, Air, Soil Pollutions, 1995, vol. 80 (1-4), pp. 373-382.

13. Siwik E.I.H., Campbell L.M., Mierle G. Fine-scale mercury trends in temperate deciduous tree leaves from Ontario, Canada. Science of the Total Environment, 2009, vol. 407, pp. 6275-6279.

14. Vetchinnikova L.V., Kuznetsova T.Y., Titov A. F. Patterns of heavy metal accumulation in leaves of trees in urban areas in the north. Karelskiy nauchny centr Rossiyskoy akademii nauk, 2013, no. 3, pp. 68-73. In Rus.

15. Pac A.Ch., Sosnovskaya N.E. Osobennosti akkumulyatsii pyli i tyazhelykh metallov drevesnymi rasteniyami $\mathrm{v}$ tekhnogennykh usloviyakh (na primere g. Grodno) [Features of accumulation of dust and heavy metals by woody plants in technogenic conditions (for example, Grodno)]. Prirodopolzovanie: sostoyanie $i$ perspektivy razvitiva. Materialy konferentsii molodykh uchenykh [Nature management: state and prospects of development. Materials of Conference of young scientists]. Minsk, 26-27 March 2014. pp. 71-75.

16. Austruya A.L., Yungc L., Ambrosib J.P., Girardclosc O., Kellerb C., Angelettib B., Dron J., Chamareta P., Chalotc M. Evaluation of historical atmospheric pollution in an industrial area by dendrochemical approaches. Chemosphere, 2019, vol. 220, pp. 116-126.

17. Tomas N., Martin S., James B.S., Jan R., Maria H., Jakub H. The history of mercury pollution near the Spolana chlor-alkali plant (Neratovice, Czech Republic) as recorded by Scots pine tree rings and other bioindicators . Science of the Total Environment, 2017, vol. 586, pp. 1182-1192.
18. Getko N.V. Ustoychivost introdutsirovannykh rasteniy k gazoobraznym soedineniyam sery [Resistance of introduced plants to sulfur gas compounds]. Optimizatsiya okruzhayushchey sredy sredstvami ozeleneniya (Promyshlennye centry Belorussii) [Optimization of the environment by means of landscaping (Industrial centers of Belarus)]. Minsk, Nauka i tekhnika Publ., 1985. pp. 60-68.

19. Assad M., Parelle J., Cazaux D., Gimbert F., Chalot M., TatinFroux F. Mercury uptake into poplar leaves. Chemosphere, 2016, no. 146, pp. 1-7.

20. Laacouri A., Nater E.A., Kolka R.K., Distribution and uptake dynamics of mercury in leaves of common deciduous tree species in Minnesota, U.S.A. Environmental Science \& Technology, 2013, vol. 47, pp. 10462-10470.

21. Ericksen J.A., Gustin M.S., Schorran D.E., Johnson D.W., Lindberg S.E., Coleman J.S. Accumulation of atmospheric mercury in forest foliage. Atmospheric Environment, 2003, vol. 37, pp. 1613-1622.

22. Muhammad S., Camille D., Sana K., Eva S., Tiantian X., Nabeel K.N. Foliar heavy metal uptake, toxicity and detoxification in plants: a comparison of foliar and root metal uptake. Journal of Hazardous Materials, 2017, vol. 325, pp. 36-58.

23. Ofitsialny sayt goroda Novosibirsk [Official WEB site of the Novosibirsk city]. Available at: http://novo-sibirsk.ru (accessed 10 January 2020).

24. Sostoyanii $i$ ob olhrane okruzhayushchey sredy Novosibirskoy oblasti $v 2018$ godu [On the state and protection of the environment of the Novosibirsk region in 2018]. Available at: https://www.nso.ru/page/2624 (accessed 11 January 2020).

25. Devyatova A.Yu. Tyazhelye metally $v$ deponiruyushchikh sredakh $i$ prognoznaya model perenosa primesey ot stacionarnykh tekhnogennykh istochnikov: na primere g. Novosibirska. Avtoreferat Diss. Kand. nauk [Heavy metals in depositing environments and a predictive model of transport of pollutants from stationary man-caused sources: the example of Novosibirsk. Cand. Diss. Abstract]. Novosibirsk, 2006. 22 p.

26. Sostoyanie okruzhayushchey prirodnoy sredy $v$ Novosibirskoy oblasti v 2000 godu: Doklad departamenta prirodnykh resursov po Sibirskomu region [The state of the environment in the Novosibirsk region in 2000: report of the Department of Natural Resources for the Siberian region]. Eds. G.V. Seliverstova, V.Yu. Alexandrova. Novosibirsk, 2001. 144 p.

27. Zyrin N.G., Malahov S.G. Metodicheskie rekomendatsii po provedeniyu polevykh i laboratornykh issledovaniy pochv $i$ rasteniy pri kontrole zagryazneniya okruzhayushchey sredy metallami [Guidelines for conducting field and laboratory studies of soils and plants in the control of environmental pollution by metals]. Ed. by N.G. Zyrin. Moscow, Gidrometeoizdat Publ., 1981. 110 p.

28. Shiyatov S.G., Vaganov E.A., Kirdyanov A.V., Kruglov V.B., Mazepa V.S, Naurzbaev M.M., Khantemirov R.M. Metody dendrokhronologii [Methods of dendrochronology]. Krasnoyarsk, KrasGU Publ., 2000. 80 p.

29. Yusupov D.V., Rikhvanov L.P., Robertus Yu.V., Lyapina E.E., Tursunalieva E.M., Baranovskaya N.V., Osipova N.A. Mercury in poplar leaves in the urbanized areas of Southern Siberia and the Far East. Ekologiya i promyshlennost Rossii, 2018, vol. 22, no. 12, pp. 56-62. In Rus.

30. Dobrovolskiy V.V. Osnovy biogeohimii [Basics of biogeochemistry]. Moscow, Akademiya Publ., 2003. 400 p.

31. Ivanov V.V. Ekologicheskaya geokhimiya elementov [Environmental geochemistry of elements]. Moscow, Ekologiya Publ., 1997. 576 p.

32. Ofitsialny sayt NZKHK [Official WEB site of NCCP]. Available at: http://www.nccp.ru (accessed 11 January 2020).

33. Artamonova S.Yu. Uranium and thorium in aerosol fallout of Novosibirsk and its environs (Western Siberia). Bulletin of the Tomsk Polytechnic University. Geo-Assets Engineering, 2020, vol. 331, no. 7, pp. 212-223. In Rus.

34. Yusupov D.V., Rikhvanov L.P., Sudyko A.F., Baranovskaya N.V., Dorokhova L.A. Radioactive elements (thorium, uranium) in poplar leaves in urbanized areas and their indicator role. Razvedka $i$ ohrana nedr, 2019, no. 2, pp. 61-68. In Rus.

35. Vse o vegetatsionnom periode rasteniy: sroki, metody vozdeystviva [Everything about the growing season of plants: timing, methods of exposure]. Available at: https://ferma.expert/rasteniya/ vegetacionnyj-period-rastenij (accessed 24 February 2020).

Received: 23 March 2020. 
Information about the authors

Elena M. Tursunalieva, postgraduate student, National Research Tomsk Polytechnic University.

Dmitry V. Yusupov, Cand. Sc., associate professor, Amur State University.

Leonid P. Rikhvanov, Dr. Sc., professor, National Research Tomsk Polytechnic University.

Elena E. Lyapina, Cand. Sc., senior researcher, Institute of Monitoring of Climatic and Ecological Systems of the Siberian Branch of the Russian Academy of Sciences. 